\title{
Catalytic Wet Oxidation of Paper Mill Debarking Water: Factors Affecting it Daniel Adjah Anang ${ }^{1,2 *}$
}

${ }^{1}$ Laboratory of Separation Technology, Department of Chemical Technology, Lappeenranta University of Technology, Skinnarilankatu 34, 53850 Lappeenranta, Finland. ${ }^{2}$ Kwame Nkrumah University of Science and Technology, Kumasi, Ghana.

\begin{abstract}
The research seeks to investigate the effect of catalyst (1-wt \% Platinum on activated carbon) on the wet oxidation process of treating paper mill effluent. The study also assesses the effect of temperature, oxygen partial pressure and initial Chemical Oxygen Demand (COD) concentration of debarking wastewater on the contaminants during the catalytic wet oxidation process.

Catalytic wet oxidation process was studied at $120-180^{\circ} \mathrm{C}$ temperature, $0-10$ bar oxygen partial pressure, $0-1$ $\mathrm{g} / \mathrm{L}$ catalyst concentration and 1000-3000 mg/L initial COD concentrations. Responses such as COD, Total Organic Carbon (TOC), Color, Lignin/Tannin, Biochemical Oxygen Demand (BOD) and pH were measured and analyzed.

In the study, it was realized that changes in temperature, oxygen partial pressure, catalyst concentration and initial COD influenced the oxidation process with the best combination occurring at a temperature of $180^{\circ} \mathrm{C}, 10 \mathrm{bar}$ oxygen partial pressure, $1 \mathrm{~g} / \mathrm{L}$ catalyst concentration and $3000 \mathrm{mg} / \mathrm{L}$ initial COD concentration. At these conditions; $74 \%$ of COD, $97 \%$ of lignin/tannin, $54 \%$ of TOC and $90 \%$ of color were removed from the wastewater.
\end{abstract}

Keywords: Paper mill effluent; Chemical oxygen demand; Catalytic wet oxidation; Debarking wastewater; Catalyst

Nomenclature: Biodegradability: BOD/COD; BOD: Biochemical Oxygen Demand, mg $\mathrm{O}_{2} / \mathrm{L}$; Co: Cobalt; COD: Chemical Oxygen Demand, mg/L; CWO: Catalytic Wet Oxidation; Lig/tan: Lignin and tannin concentration, $\mathrm{mg} / \mathrm{L}$; Pt: Platinum; TOC: Total Organic Carbon, mg/L; Wt: Weight; WO: Wet oxidation

\section{Introduction}

Pulp and paper industries use tons of water during wood processing and paper making. The water becomes contaminated as it removes toxic and hazardous organic chemicals from the wood material which may eventually be released into freshwater ecosystems. Their toxic nature is derived from the presence of several naturally occurring and xenobiotic compounds which are formed and released during various stages of papermaking $[1,4]$. These chemicals end up causing problems to the environment.

Environmental conservation drive and policies to produce less toxic wastewater before discharging into the ecosystem have compelled wood and paper industries to treat their wastewater to meet acceptable standards before discharging or recycling it in the process.

Many wastewater treatment methods are already developed and are in use. Most of these conventional methods are incapable of effectively removing all organic pollutants. Biological treatment is very effective for many industrial pollutants. However, wastewaters produced by paper mills contain organics that are non-biodegradable or toxic and are found in high concentrations therefore making biological treatment not very effective.

Therefore, the search for an intensified, efficient and better technology development to treat paper mill wastewater has been a major concern throughout the world.

Wet oxidation (WO) process, a technique governed by generation of active species at high temperature and pressure such as hydroxyl radicals, is known to have a great potential for the treatment of effluent containing high content of organic matter (chemical oxygen demand (COD) $10-100 \mathrm{~g} / \mathrm{l}$ ), or toxic contaminants for which direct biological purification is unfeasible [2]. WO does not completely oxidize pollutants resulting in the formation of organic intermediates. The efficiency of aqueous phase oxidation can be significantly improved by the use of catalysts, resulting in the formation of inorganic products like $\mathrm{CO}_{2}$ and $\mathrm{H}_{2} \mathrm{O}$ [3]. Thus, Catalytic Wet Oxidation (CWO) is an improvement on WO since it reduces cost and gives higher oxidation rates.

This work therefore seeks to study the influence of temperature, oxygen partial pressure, catalysts loading and initial COD concentration of debarking wastewater on the contaminants during the CWO process. The study of WO of debarking wastewater is presented in the work done by Kindsigo and Kallas [5].

\section{Materials and Methods}

\section{Materials and analyzes}

The feed for this study was a concentrated dark brown debarking wastewater obtained from a Finnish paper mill. A Pt (1-wt \%) on activated carbon catalyst was used for the investigation. Millipore water was used in almost all the analyses (COD, BOD, Lignin/tannin, color, etc). The lignin concentration was measured with a photometric method developed by Hach Company. Sodium Carbonate solution and "Hach Co." tannin-lignin reagent react with lignin forming bluecolored intermediates. After $25 \mathrm{mins}$ of reaction, the color intensity was measured.

The lignin content, color and aldehydes were measure by a directread HACH DR/2000 spectrophotometer at wavelengths of 700 , 455 and $630 \mathrm{~nm}$ respectively. COD was measured by a closed reflux dichromate method, using a COD reactor (Hach Company, USA)

*Corresponding author: Daniel Adjah Anang, Kwame Nkrumah University of Science and Technology, KNUST, Kumasi, Ghana, Tel: +233546240089; E-mail: taadjah@yahoo.com

Received June 06, 2011; Accepted July 06, 2011; Published July 15, 2011

Citation: Anang DA (2011) Catalytic Wet Oxidation of Paper Mill Debarking Water: Factors Affecting it. Hydrol Current Res 2:116. doi:10.4172/2157-7587.1000116

Copyright: @ 2011 Anang DA. This is an open-access article distributed under the terms of the Creative Commons Attribution License, which permits unrestricted use, distribution, and reproduction in any medium, provided the original author and source are credited. 
and a spectrophotometer DR/2000 (Hach Company, USA). The biochemical oxygen demand was assessed by standard $\mathrm{BOD}_{5}$ test. TOC was measured using a Shimadzu 5050 TOC analyzer.

\section{Experimental procedure}

The experiment was performed in a $450 \mathrm{~mL}$ high pressure stainless steel batch reactor manufactured by Parr Instrumental Company, U. S. A. It's a cylindrical vessel which works best up to a pressure of 5 $\mathrm{MPa}$ and $350^{\circ} \mathrm{C}$ and supported by two semi-circular metals and a screw which allows the reactor to function safely. It is well equipped with a four blade turbine type impeller stirrer to maintain uniform mixing and provided with an external heater in the form of a jacket to provide heat needed for reaction. It also has an interconnected refrigeration or cooling system which works well together with the heater to maintain a particular temperature needed for oxidation. It has a gas inlet, liquid sampling tube and gas release valves.

A $300 \mathrm{~mL}$ of the filtered wastewater is loaded into the reactor. When necessary, the catalyst is weighed and added to the wastewater. After the reactor is properly sealed, it is placed in the heating jacket and heated to the required reaction temperature. Oxygen is introduced into the reactor through the gas inlet when the set temperature is attained. The reaction medium is stirred thoroughly by the stirrer. Sample of the wastewater were taken during the experiment. The first sample was taken before the reactor was loaded. This is referred to as sample at $\mathrm{t}=-30$ minutes. The second sample was drawn off immediately after preheating and before the oxygen valves were opened. That is sample at $\mathrm{t}=0$. The rest of the samples were taken at times $\mathrm{t}=10,20,30,60$, 90 and 120 minutes after reaction had started and were analyzed. These analyses include COD, BOD, Total Organic Carbon (TOC), lignin/tannin, color and $\mathrm{pH}$. Biodegradability (BOD/COD) was also determined for the wastewater.

\section{Discussion of Results}

\section{Influence of temperature}

Different experimental runs were conducted at temperatures of $120^{\circ} \mathrm{C}, 150^{\circ} \mathrm{C}$ and $180^{\circ} \mathrm{C}$ for 11 different experiments with different combination of temperature and other input factors.

Figure 1 shows the percentage reduction of COD with respect to time. All results showed reduction in COD within 2 hours. It can be observed that the lowest amount of COD removed (about 10\%) within 2 hours was achieved at a temperature of $120^{\circ} \mathrm{C}$, which was the lowest. Similarly, the highest COD removed (about 74\%) was achieved at a
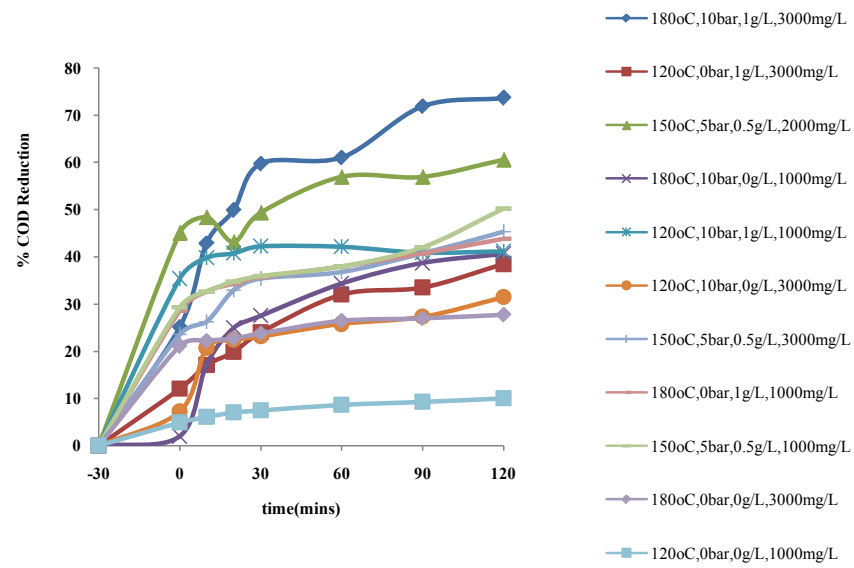

Figure 1: COD removal against time.

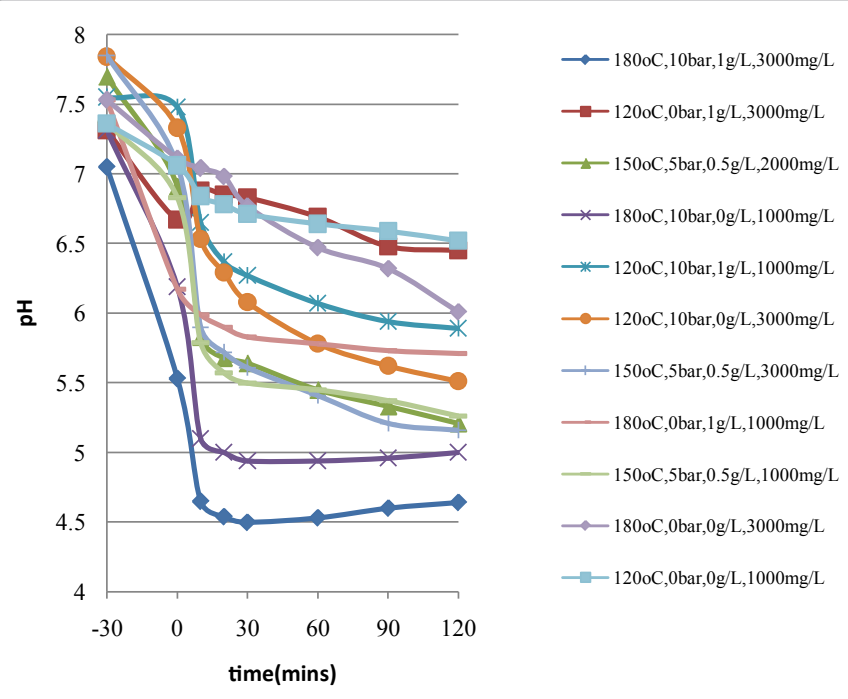

Figure 2: $\mathrm{pH}$ measured against time.

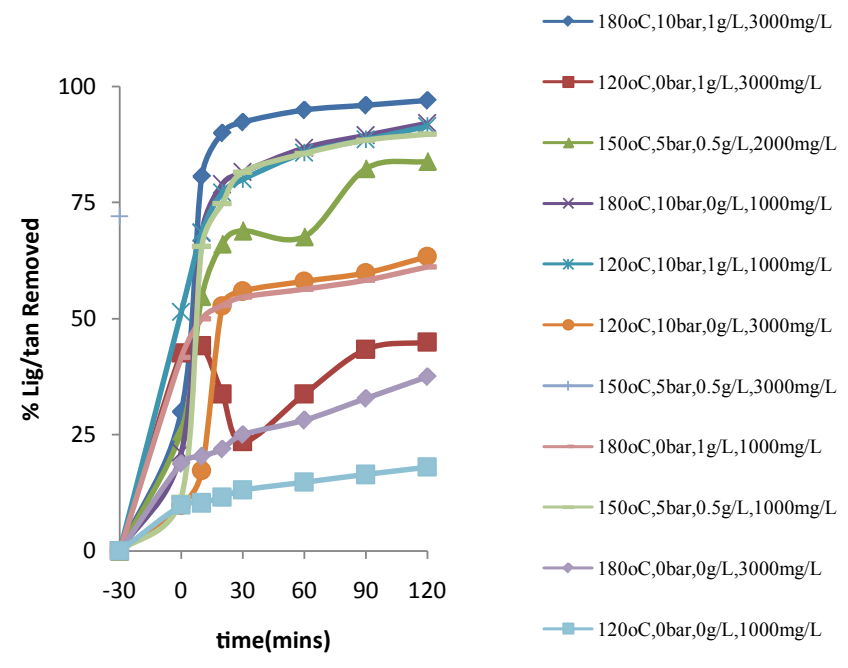

Figure 3: Lignin/tannin removal against time.

temperature of $180^{\circ} \mathrm{C}$, which was the highest.

In Figure 2, the $\mathrm{pH}$ of the debarked wastewater during the CWO is depicted against time. The $\mathrm{pHs}$ decreased generally from neutrality to acidity for all experiments. This may be as a result of organic pollutants decomposing into organic acids during the oxidation process. However, the rate of decomposition depends on the conditions used. As can be seen on the plot, higher temperatures reduced $\mathrm{pH}$ greatly. Moreover, there was a sharp decrease in $\mathrm{pH}$ during the preheating period. This is because the organic pollutants decompose into organic acids immediately they are exposed to high temperatures. Higher temperature exposure leads to higher rate of decomposition.

Figure 3 shows a chart of Lignin and tannic acid reduction (in percentage) of the debarked wastewater with respect to time. All experiment showed reduction in lignin/tannin from the wastewater. The highest lignin/tannin removal (about 97\%) occurred at a temperature of $180^{\circ} \mathrm{C}$ while the least (about $18 \%$ ) occurred at $120^{\circ} \mathrm{C}$ 
within 2 hours. Moreover, more than 50\% lignin/tannin removal occurred mostly at temperatures of $150^{\circ} \mathrm{C}$ and $180^{\circ} \mathrm{C}$. In most of the experiments, preheating period alone produced more than $10 \%$ lignin/ tannin removal.

Figure 4 depicts the rate of biodegradability within 2 hours. Most of the study revealed slight decrease in biodegradability during preheating before rising. Higher values of biodegradability explain the degree of decomposition of organic matter through biological activity. According to Donlagic and Levec [6], wastewater with higher ratios of biodegradability (over 0.5) means that the wastewater is easily biodegradable. In Figure 4, most of the ratios are between 0.1 and 0.5. Hence further biological treatment may not be necessary.

Experiments carried at high temperatures showed higher values of biodegradability.

From the study conducted, it was realized that the decomposition of organic pollutants into acids and inorganic minerals occurred at elevated temperatures. Lower temperatures gave least decomposition rates. This is so because oxygen must first diffuse into the liquid phase for WO reaction to occur, its solubility in water is critical since it depends on temperature. The higher the temperature, the more soluble the oxygen becomes in water and the higher the reaction rates. Increase in temperature between $120^{\circ} \mathrm{C}$ and $180^{\circ} \mathrm{C}$ improved reduction in COD, TOC, Color and Lignin/tannin concentrations as well as $\mathrm{pH}$ observed.

\section{Influence of initial COD concentration}

Measurement and analyses of responses showed that color and lignin behaved to study the effect of initial COD concentration on the wastewater during the CWO process, three of the experiments were conducted at different initial COD concentrations while other input parameters (temperature, oxygen partial pressure and catalyst concentration) were kept constant.

As shown on figures 5 and 6 , the least concentrated solution gave the best response. For instance, a debarking wastewater operated at $150^{\circ} \mathrm{C}$, 5 bar oxygen partial pressure and $0.5 \mathrm{~g} / \mathrm{L}$ catalysts concentration having an initial COD concentration of $1000 \mathrm{mg} / \mathrm{L}$ reduced TOC and Color to $36.5 \%$ and $81.0 \%$ respectively within 2 hours. Meanwhile the ones operated at similar conditions but higher initial COD concentrations reduced TOC and Color by lesser amounts.

The study proves that the initial COD concentration of the wastewater determines to some extent how long such wastewater can be treated. Under the same conditions, wastewater with lower initial

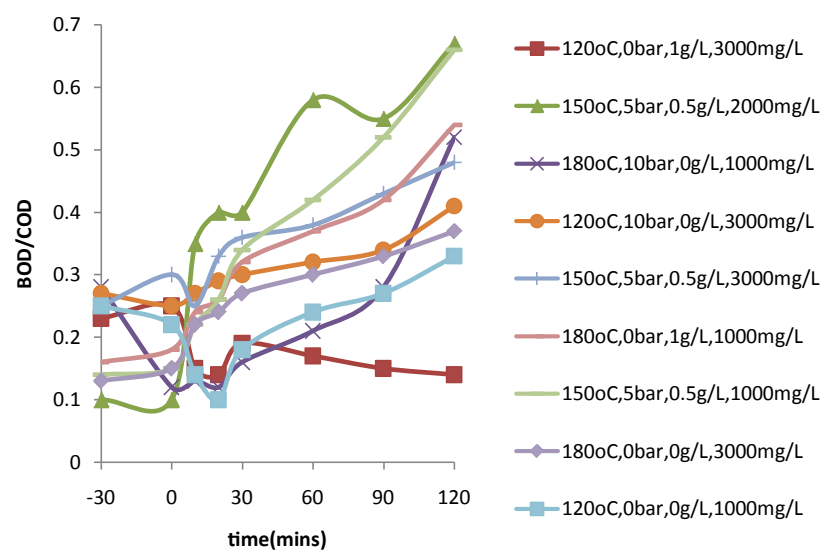

Figure 4: Biodegradability against time.

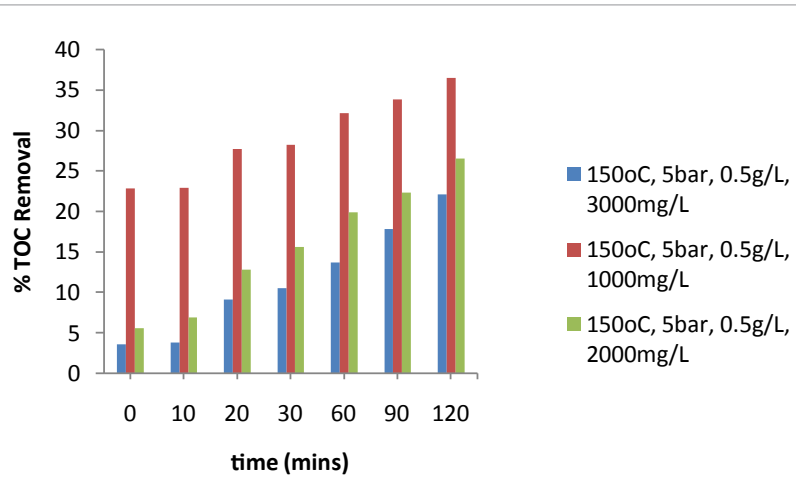

Figure 5: TOC reduction against time for 3 selected experiments.

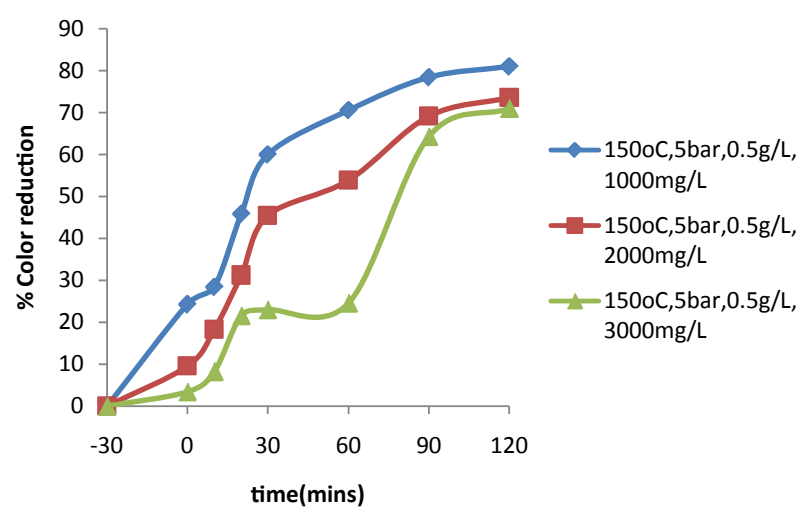

Figure 6: Color removal against time.

COD concentration will take lesser time to be treated compared to that with higher initial COD concentration.

\section{Influence of oxygen partial pressure}

Oxygen partial pressure helped in the removal of contaminants from the wastewater. To see how this affects the various outputs, some experimental runs where analyzed. The results are showed in Figure 7 and Figure 8.

Rates of decomposition of COD and TOC are shown in Figure 7 and Figure 8 respectively. As can be seen from these pictures, oxygen partial pressure clearly differentiates the cases giving high TOC and COD reduction to $54 \%$ and $75 \%$ respectively within 2 hours.

The role of oxygen pressure is to maintain oxygen in the liquid phase. A higher pressure will increase the dissolved oxygen concentration which is important for wet oxidation whiles a lower pressure will liberate oxygen from the liquid phase.

\section{Influence of catalyst concentration}

Studying the effect of catalyst concentration on contaminants removal from the wastewater, the responses of some experiments are presented. Figure 8 shows the measured $\mathrm{pH}$ with time for four comparable experiments.

Figure 9 depicts the $\mathrm{pHs}$ of four experiments at the same temperature $\left(120^{\circ} \mathrm{C}\right)$. Two of the results (experiments without catalyst addition) showed narrow $\mathrm{pH}$ ranges of 7.31 to 6.45 and 7.36 to 6.52 . This means, they did not decompose much of the organic pollutants 
in the wastewater to organic acids. The other results (cases where catalyst were used) showed wider $\mathrm{pH}$ ranges with the highest catalyst concentration used giving the widest $\mathrm{pH}$ range.

Figure 9 shows that increasing catalyst concentration between 0 and $1 \mathrm{~g} / \mathrm{L}$ favored higher decomposition of organic pollutants into organic acids and hence catalyst concentration helped in the total removal of contaminants from the water.

One disadvantage of adding Platinum on activated carbon catalyst is that it increases the TOC content of the wastewater. Interestingly, it aids in removing significant amount of pollutants, including TOC, from the wastewater.

\section{Optimum operating condition}

From the responses measured and analyzed, it can be inferred that

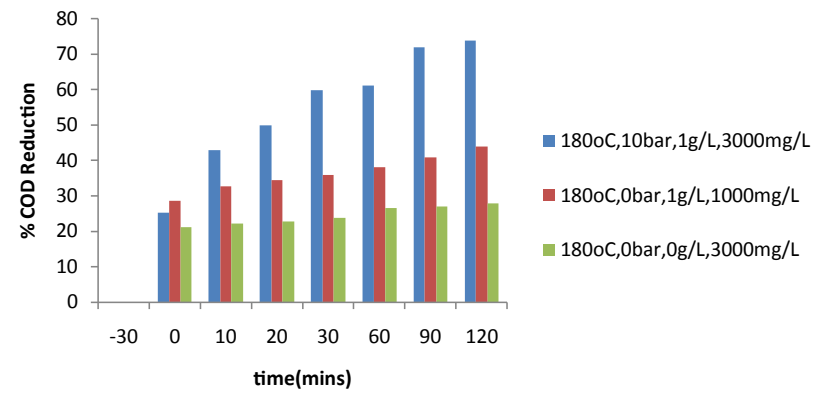

Figure 7: COD removal against time for selected experiments.

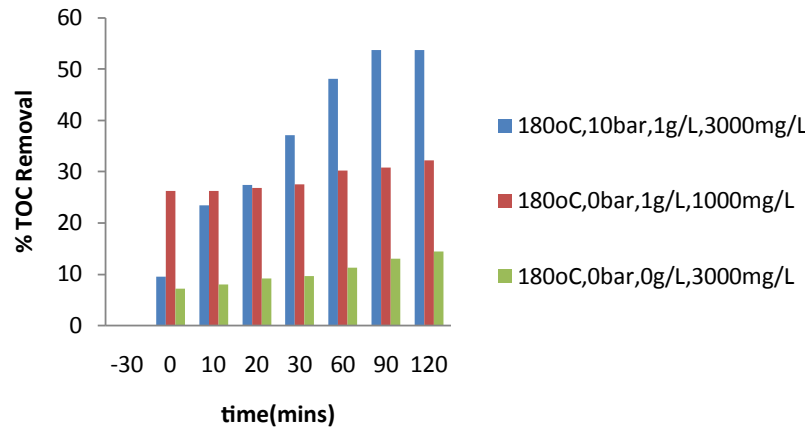

Figure 8: TOC removal against time for selected experiments.

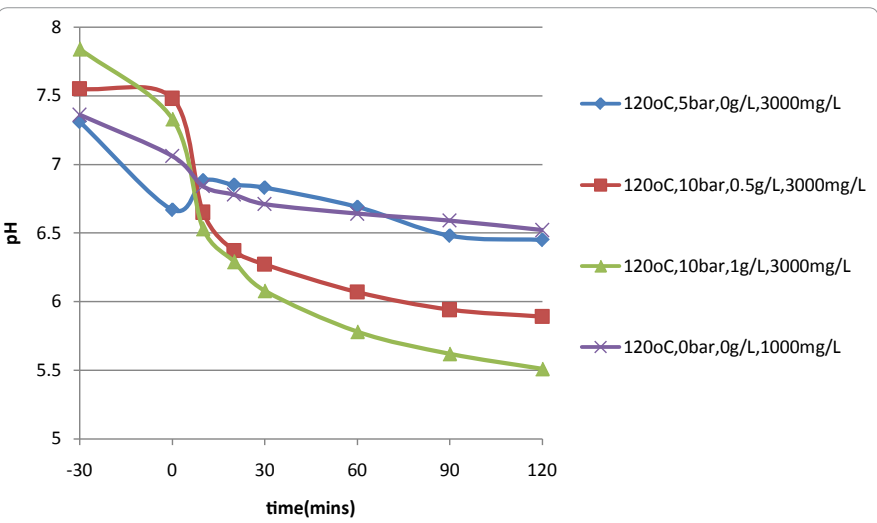

Figure 9: Measured $\mathrm{pH}$ against time for selected experiments.

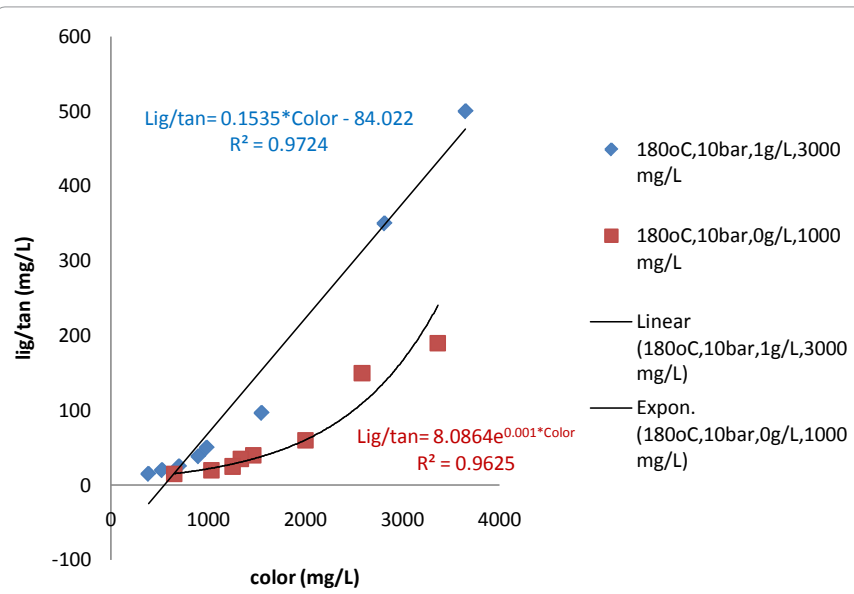

Figure 10a: Lignin/tannins concentration against color intensity

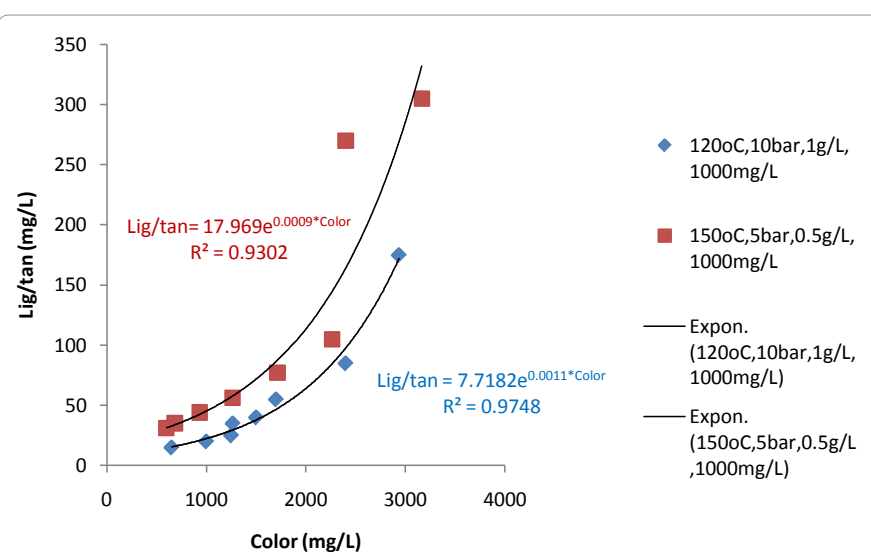

Figure 10b: Lignin/tannins measured versus color measured.

the best operating conditions were attained at $180^{\circ} \mathrm{C}, 10$ bar oxygen pressure, $1 \mathrm{~g} / \mathrm{L}$ catalyst concentration and $3000 \mathrm{mg} / \mathrm{L}$ initial COD concentration. At these conditions; $74 \%$ of COD, $97 \%$ of lignin/tannin, $54 \%$ of TOC and $90 \%$ of color were removed from the wastewater.

\section{Correlation between different responses}

similarly during the catalytic wet oxidation process. Their behavior are summed up in Figure 10a and b. Figure 10a and b show the dependency curves of lignin/tannin on color for some experiments. They indicate the lig/tan and color mathematical relationship as well as their $\mathrm{R}^{2}$ values. The model derived (in Figure 10a and b) can be used for predicting the lignin/tannin content by means of color analysis. Since there are high correlations ( $\mathrm{R}^{2}$ closer to 1 ) between lignin/tannin and color, it can be concluded that the lignin and tannins in the wastewater are strongly responsible for the dark brown color of the debarked water.

\section{Conclusion}

Catalytic wet oxidation technology is very ripe for the treatment of debarking wastewater. It is able to remove toxic substances such as lignin and tannins, chlorinated compounds and resin acids from wastewater which is not effectively done by conventional treatment methods. Appreciable levels of contaminants such as COD, TOC, lignin/tannin, etc were removed from the debarked wastewater at every specific operating condition. Lignin/tannin was greatly removed. 
Increasing temperature between $120^{\circ} \mathrm{C}$ and $180^{\circ} \mathrm{C}$ favored higher CWO rate, allowing a faster oxidation of contaminants. Oxygen pressure increment between 0 and 10 bar resulted in the improvement of the CWO process. For catalyst concentration, higher oxidation rates of the organics were achieved by increasing catalyst concentration between 0 and $1 \mathrm{~g} / \mathrm{L}$.

Color and lignin/tannin removal showed high linear dependency during the CWO process. It is therefore concluded that lignin/tannin were responsible for the dark brown color of concentrated debarked water.

\section{Acknowledgement}

I sincerely wish to express my profound appreciation to Lappeenranta University of Technology for providing all the needed financial and material assistance for this research. Special thanks go to Professor Juha Kallas (now retired) for supervising this work

\section{References}

1. Ali M, Sreekrishnan RT (2001) Aquatic toxicity from pulp and paper mill effluents: a review. Advances in Environmental Research 5: 175-196.

2. Mishra SV, Mahajani VV, Joshi JB (1995) Reviews, Wet air oxidation. Ind Eng Res 34: 2-48.

3. Pintar A (2003) Catalytic processes for the purification of drinking water and industrial effluents. Catalysis Today 77: 451-465.

4. Pokhrel D, Viraraghavan T (2004) Treatment of pulp and paper mill wastewater-a review. Science of the Total Environment 333: 37- 58.
5. Kindsigo M, Kallas J (2009) Wet oxidation of debarking water: changes in lignin content and biodegradability. Environ Chem Lett 7: 121-126.

6. Donlagic J, Levec J (1998) Comparison of catalysed and noncatalysed oxidation of azo dye and effect on biodegradability. Environ Sci Technol 32: 1294-1302.

7. Baillod CR, Lampaarter RA, Barna BA (1985) Wet oxidation for industrial waste treatment. Chemical Engineering Progress 3: 52-55.

8. Bhargava SK, Tardio J, Föger K, Akolekar DB, Grocott SC, et al. (2006) Reviews. Wet oxidation and catalytic wet oxidation. Ind Eng Chem Res 45:1221-1258.

9. Debellefontaine H, Chakchouk M, Foussard JN, Tissot D, Striolo P (1996) Treatment of organic aqueous wastes: wet air oxidation and wet peroxide oxidation. Environmental Pollution 92: 155-164.

10. Leach JM, Thakore AN (1976) Toxic constituents in mechanical pulping effluents. Tappi J. 59: 129-132.

11. Luck $F$ (1996) A review of industrial catalytic wet air oxidation processes Catalysis Today 27: 195-202.

12. Luck F (1999) Wet air oxidation: past, present and future. Catalysis Today 53 81-91.

13. Pintar A, Levec J (1992) Catalytic liquid phase oxidation of refractory organics in waste water. Chem Eng Sci 47: 2395-2400.

14. Verenich S, Roosalu K, Hautaniemi M, Laari A, Kallas J (2005) Kenetic modelling of promoted and unpromoted wet oxidation of debarking evaporation concentrates. Chem Eng J 108: 101-108. 